\title{
Cinco Cosas que el Productor Agrícola puede Hacer para Mejorar las Ganancias de su Negocio ${ }^{1}$
}

Edward Evans ${ }^{2}$

\section{Introducción}

El negocio de producción agrícola está cambiando considerablemente. Hace tiempo que han pasado los días cuando el productor agrícola podía darse el lujo de ignorar lo que pasaba fuera del área local y todavía esperaba tener ganancias. En el mundo de hoy, caracterizado por una globalización cada vez mayor de la competencia, los productores deben estar enterados de lo que ocurre en el mundo y deben tomar decisiones basados en un volumen cada vez mayor de información. Una mejor administración financiera es el factor más importante para tener éxito en un mercado global competitivo. Este artículo resume las cinco cosas que los productores pueden hacer para mejorar las ganancias de sus negocios agrícolas.

\section{Mejorar el Mantenimiento de Registros}

Información es poder y poder es dinero. Aunque la idea del mantenimiento de registros financieros no es nueva, estos se han vuelto de suma importancia debido a la competencia global y a la disminución de los márgenes de ganancia.

Frecuentemente hay una línea muy delgada entre los negocios que son lucrativos y los que no lo son. Para que el negocio sea lucrativo, las decisiones deben ser tomadas basadas en información cierta.

Computadoras y programas (software) financieros tales como Quicken han simplificado mucho el mantenimiento de registros (Brooks, 2005).

Además, los programas financieros ahorran tiempo, son fáciles de usar y pueden usarse para mantener muchos tipos de registros financieros, desde simple teneduría de libros (balance de cheques, control de empleados y reportes de planillas) hasta análisis financieros complejos (generar presupuestos enteros de fincas a partir de datos corrientes e históricos, crear reportes de transacciones, y resumir datos de contabilidad tales como hojas de balance y reportes de impuestos). Por estas razones, los productores deben comprar computadoras y programas financieros.

1. Este documento, FE623, es uno de una serie de publicaciones del Departamento de Food and Resource Economics, Servicio de Extensión Cooperativa de la Florida, Instituto de Alimentos y Ciencias Agrícolas, Universidad de la Florida. (UF/IUFAS). Fecha de primera publicación: December 2005. Este traducción del FE569, publicado Augusto 2005. La traducción del inglés al español estuvo a cargo de Carols Jauregui. Visite nuestro sitio web EDIS en $<$ http://edis.ifas.ufl.edu>.

2. Edward Evans, Profesor Asistente, Departamento de Food and Resource Economics, Servicio de Extensión Cooperativa de la Florida, Instituto de Alimentos y Ciencias Agrícolas, Universidad de la Florida. Gainesville, FL.

El Instituto de Alimentos y Ciencias Agrícolas es un empleador que opera bajo Acción Afirmativa y provee Oportunidades Igualitarias, autorizado a proveer investigación, información educativa y otros servicios, únicamente a los individuos e instituciones que operan sin discriminación alguna con relación al credo, color, religión, edad, incapacidad, sexo, orientación sexual, estado civil, nacionalidad, opinion política o afiliaciones. Para más información sobre como obtener otras publicaciones de extensión, comuníquese con la oficina de Servicio de Extensión de su condado. Servicio de Extensión de la Florida / Instituto de Alimentos y Ciencias Agrícolas / Universidad de la Florida / Larry Arrington, Decano. 


\section{Conducir Análisis Financieros}

Mientras que mantener un buen registro financiero es importante, esto no garantiza que el negocio sea lucrativo. Un criterio más importante es el de analizar la información que muestran las hojas de balance, el estado de cuenta de ingresos y el estado de cuenta del flujo de dinero en efectivo. Analizando los componentes y las relaciones entre estos tres estados de cuenta financieros ayuda a los productores a entender qué tan bien está yendo el negocio y provee una idea de posibles áreas problemáticas. Por ejemplo, un análisis del estado de cuenta del dinero en efectivo identifica periodos con posible insuficiencia o exceso de dinero en efectivo y provee información útil para tratar con los prestamistas y para planear pagos. Un análisis de la hoja de balance identifica el valor neto del negocio (eso es, qué porción del negocio le pertenece al productor) y provee información para planear y tomar riesgos. El análisis del estado de cuenta de ingresos indica si el negocio es rentable y señala la fuente de donde provienen las ganancias. Un análisis del estado de cuenta financiero debe conducirse cuando menos una vez al año y de preferencia cada trimestre.

\section{Controlar Costos}

Una razón por la cual un negocio agrícola no es lucrativo podría ser altos costos de producción. Este es típicamente el caso cuando los ingresos brutos son altos y los ingresos netos son bajos. Siguiendo la pista de los ingresos y gastos a través de los estados de cuenta financieros, y examinando el estado de cuenta del dinero en efectivo uno puede identificar el problema y tomar medidas para remediarlo (Cuadro 1). Por ejemplo, los registros del negocio pueden ser estudiados para ver si los insumos se están comprando a precios competitivos y si están siendo utilizados completamente. Además, siempre se debe consultar con los agentes locales de extensión a cerca de tecnologías de producción de bajo costo.

\section{Incrementar Ingresos}

Otra razón por la cual un negocio agrícola no es lucrativo podría ser debido a bajos ingresos. Incrementando el tamaño de las operaciones o usando mejores tecnologías, tales como variedades más productivas, puede incrementar el ingreso bruto así como el ingreso neto. Sin embargo, se debe tener cuidado en asegurar que los costos no excedan los beneficios (vea la publicación EDIS, documento FE565, Marginal Analysis, http://edis.ifas.ufl.edu/FE565). Otras maneras de incrementar los ingresos incluyen mercadeo directo, dándole un valor adicional (transformando) al producto, usando mercados especializados y mejorando la calidad del producto.

El mercadeo directo se ha vuelto muy popular entre los pequeños productores debido a los avances en la tecnología de la información, a las preocupaciones por la salud personal, el medio ambiente y la sanidad de los productos alimenticios. El mercadeo directo incluye la agricultura apoyada por la comunidad (community-supported agriculture, CSA), catálogos, ventas a través de la internet y de mercados locales (Macher, 1999; vea también la publicación EDIS FE548, Seis Maneras de Mejorar las Ganancias de Lichi en el Sur de Florida, http://edis.ifas.ufl.edu/FE548).

Darle valor adicional al producto quiere decir transformarlo de su forma original a una forma más conveniente para su consumo. Por ejemplo, cortando la piña en rebanadas le da valor adicional. Otros ejemplos de darle valor adicional a las frutas incluyen mermeladas, vinos, salsas, helados, frutas secas, vinagres y frutas cubiertas con chocolate.

Mercados especializados pueden ser lucrativos para operaciones pequeñas. Negocios grandes proveen principalmente a los segmentos más lucrativos de los mercados grandes y generalmente ignoran a los pequeños segmentos de mercados especializados, los cuales pueden pagar precios altos.

Mejorar la calidad parece obvio pero envuelve mejorar tanto la apariencia física del producto como las condiciones de producción (eso es, tratamiento humanitario de los animales, y protección o preservación de los recursos naturales y el medio ambiente). 


\section{Diversificar el Negocio}

En la economía de hoy, los productores deben evaluar sus negocios constantemente para poder eliminar los que producen pérdidas y crear nuevos o expandir los lucrativos. Mientras que los principios económicos sugieren especialización para maximizar ganancias, la competencia global y un aumento en los riesgos, especialmente en el caso de pequeños productores, incentiva a escoger una mezcla de negocios lucrativos. Diversidad en los negocios puede proveer estabilidad económica. Cuando se considere aumentar nuevas empresas al negocio se debe hacer lo siguiente:

- Determinar si hay mercado o demanda por el producto.

- Fijar metas para la empresa.

- Determinar las habilidades necesarias para que la empresa sea lucrativa.

- Determinar la disponibilidad de servicios, equipos y recursos requeridos.

- Crear guías de inversión (esto es, cuánto se debe invertir anualmente y cuánto tiempo es posible esperar hasta que los ingresos excedan a los egresos).

- Crear presupuestos, incluyendo análisis de sensibilidad de ganancias a rendimientos, así como de variabilidad de precios.

- Evitar crear nuevas empresas que compitan por los mismos recursos (Doyle, 2004).

Se debe notar que cambiando de una empresa a otra se pueden incrementar los riesgos (de producción, financieros y de mercadeo), por eso es que un planeamiento adecuado es esencial.

\section{Comentarios Finales}

En tanto que la globalización continúe, con los países fomentando políticas de libre comercio y los gobiernos reduciendo el soporte a los productores locales, mantener ganancias en los negocios se ha vuelto incierto. Este artículo identifica cinco cosas que los productores pueden hacer para incrementar las ganancias y mejorar el manejo del negocio. La supervivencia de los negocios depende cada vez más de que los productores desarrollen mejores habilidades analíticas y de manejo de negocios.

\section{Referencias}

Brooks, K. 2005. Quicken for Farm

Producers--2005.

http://www.farmdoc.uiuc.edu/manage/quicken/ quicken.html.

Doyle, D. 2004. Evaluating Options for Change. Oklahoma Cooperative Extension Publication F-208. Oklahoma State University, Stillwater, OK. http://pods.dasnr.okstate.edu/docushare/.

Macher, R. 1999 Making Your Small Farm Profitable. North Adams, MA: Storey Publishing. 
Cuadro 1. Identificando problemas y tomando acción.

\begin{tabular}{|c|c|}
\hline Problema & Acción \\
\hline - Alto costo de tierras & - Rentar las tierras \\
\hline - Arrendamientos altos & - Renegociar los contratos de arrendamiento \\
\hline - Pagos con altos intereses & - Renegociar las tasas de interés \\
\hline - Mano de obra costosa & - Reemplazar la mano de obra con manquinarias \\
\hline - Alto costo de maquinarias & - Alquilar maquinaria \\
\hline - Altos costos de reparación y mantenimiento & - Vender o reemplazar maquinaria y equipo anticuado \\
\hline - Alto costo de insumos & - Unirse con otros para comprar en cantidad a precios de descuento \\
\hline - Altos pagos de energía & - Usar maquinaria eficiente y diferentes fuentes de energia \\
\hline
\end{tabular}

